\title{
Pérez Galdós y Gómez de la Serna: dos visiones literarias diferentes sobre el mito y la historia de Juana de Castilla*
}

\author{
Ruth MARTÍNEZ ALCORLO \\ Universidad Complutense de Madrid \\ rmalcorlo@ucm.es
}

\section{RESUMEN}

El siguiente análisis pretende ahondar en el tratamiento literario del mito de Juana I de Castilla — conocida para la historia como «la Loca»— que ofrecen Santa Juana de Castilla de Benito Pérez Galdós (1918), y Doña Juana la Loca (y otras seis novelas superhistóricas) (1944), de Ramón Gómez de la Serna. Ambas obras se despojan de los conocidos tópicos sobre la locura y la pasión de la reina gracias a la originalidad y la libertad de ambos autores a la hora de enfrentarse con el personaje: Galdós prescinde de los manidos tópicos románticos anteriores para reflexionar acerca de la dignificación histórica, mientras que Gómez de la Serna añade a la supuesta locura de Juana su obsesión por la muerte, para quien imagina un nuevo final. Así, bajo el membrete de lo superhistórico, se recrea otra personalidad y otro destino para la reina, totalmente alejados de los hechos históricos.

Palabras clave: Juana de Castilla, Pérez Galdós, Gómez de la Serna, intrahistoria, superhistoria.

\begin{abstract}
The following analysis aims to delve into the literary treatment of the myth of Joanna I of Castile - historically known as 'the Mad'—offered by Benito Pérez Galdós's Santa Juana de Castilla (1918), and Ramón Gómez de la Serna's Doña Juana la Loca (y otras seis novelas superhistóricas) (1944). Both works are separated from the well-known topics about the queen's madness and passion thanks to the liberty that both authors took and their originality when facing the character: Galdós ignores the aforementioned trite romantic topics to reflect on the historical dignification, while Gómez de la Serna added Joanna's obsession with death to her supossed madness imagining a new ending for the queen. Thus, under the letterhead of 'what is superhistorical', another personality and another destiny for the queen are recreated, both being totally divorced from the historical facts.
\end{abstract}

* El presente artículo se ha realizado gracias a la beca obtenida dentro del programa de ayudas de posgrado para la Formación del Profesorado Universitario (FPU, ref. AP2012-2654), concedida por el Ministerio de Educación, Cultura y Deporte. 
Keywords: Joanna of Castile, Pérez Galdós, Gómez de la Serna, 'innerhistory', superhistoria.

SUMARIO: 1. Introducción, 2. La propuesta de Galdós: santificación y alternativa histórica, 3. «La historia de reyes y personajes es inesperada»: Juana la Loca y la superhistoria, 4. Dos maneras de interpretar un mito. Conclusión.

\section{Introducción}

A través de los siglos y del río del tiempo, el imaginario ha (re)creado en la figura de Juana I de Castilla el mito de la locura de amor. Conocida para la historia bajo el sobrenombre de «la Loca», numerosas han sido las artes que se han acercado al personaje, como la literatura, la música o la pintura, donde la más polémica de las hijas de los Reyes Católicos ha sido objeto de múltiples interpretaciones, pero siempre sin salirse de los conocidos tópicos sobre los celos y la pasión amorosa que parecen conformar los mimbres del mito. Sin embargo, esta poderosa figura presenta una imagen poliédrica que, en palabras de Bethany Aram: «en lugar de encuadrarse en una única categoría [...], "piadosa" o "hereje", "loca" o "cuerda", Juana desafía las ideas preconcebidas y anacrónicas que sobre ella se han forjado»" ${ }^{1}$.

En tan abundante caudal interpretativo, sobresalen dos genios que rechazan de plano las interpretaciones canónicas sobre el personaje al compartir una mirada heterodoxa frente al mito. De este modo, en las obras que le dedican Benito Pérez Galdós y Ramón Gómez de la Serna surgen dos visiones literarias muy diferentes a las acostumbradas durante la segunda mitad del siglo XIX y la primera mitad del XX. Desde otra vuelta de tuerca, la originalidad y la libertad de los dos autores a la hora de enfrentarse con la figura de Juana de Castilla ofrecen otra mirada del mito que aquí analizaremos, totalmente desligada de los tópicos anteriores que rodean al personaje.

\section{La propuesta de Galdós: santificación y alternativa histórica}

En 1907, Galdós, en su extenso prólogo al libro de José María Salaverría,Vieja España, había escrito lo siguiente: «No hay drama más intenso que el lento agonizar de aquella infeliz viuda, cuya psicología es un profundo y tentador enigma. ¿Quién lo descifrará?» ${ }^{2}$. Años después, el canario, tentado por ese intenso drama, decidió convertir a Juana en protagonista de su última incursión teatral, titulada Santa Juana de Castilla, estrenada el 8 de mayo de 1918 en el teatro de la Princesa

${ }^{1}$ B. Aram (2008), p. 33: «Rather than conforming to a single category [...], 'pious' or 'heretical', 'mad' or 'sane', Juana defies preconceived and anachronistic ideas». La traducción es mía.

${ }^{2}$ B. Pérez Galdós, prólogo a J. Ma .Salaverría (1907), p. XXXIV. 
de Madrid, con Margarita Xirgu como actriz principal. En las imágenes que se conservan del estreno se puede ver a la famosa actriz caracterizada como Juana de Castilla, además de una serie de fotografías que muestran la decoración de la sala del palacio de Tordesillas, donde se enmarca la acción, con los dos retratos que presiden la escena, por una parte, el famoso lienzo de Isabel la Católica y, en frente de este, se sitúa el de Carlos V, «copia del de Ticiano, universalmente conocido» ${ }^{3}$.

La acción de la obra tiene lugar en Tordesillas, en la Semana Santa de 1555. Juana lleva cuarenta y seis años encerrada, apartada del mundo, a instancias primero de su padre, Fernando el Católico y, más tarde, de su hijo, Carlos $\mathrm{V}^{4}$. La total desatención y olvido de la que fuera reina castellana es relatada desde el inicio de la obra por dos de sus criados, Mógica y Marisancha, que plantean un conflicto teatral dicotómico, por un lado la «supuesta» locura de la reina - que no es otra cosa que la demencia provocada por la vejez, ya que para ella «es lo mismo el antaño que el hogaño» ${ }^{5}$ - por otro lado, la «supuesta» herejía, pues Juana se presenta como lectora voraz de Erasmo - en palabras de la criada: «la señora se recrea y no tiene otro devocionario que esa Locura de D. Fantasmo» ${ }^{6}$ - En consecuencia, el desarrollo dramático que se sigue refutará estos dos temas - locura y herejía - además de invitar a una reflexión personalísima del rumbo de España.

En el segundo acto, «auténtico interludio y descanso emocional para el espectador» ${ }^{7}$, Juana escapa de las manos del Marqués de Denia, su cancerbero, al pueblo cercano de Villalba del Alcor, donde actuará en todo momento con prudencia y cordura, cualidades con las que, por otra parte, se conduce en toda la obra. En esta localidad la recibe el pueblo de Castilla, el único que la reconoce como verdadera reina —anteriormente Juana se definía como «reina de nombre nada más» ${ }^{8}$ - Más aún, la soberana será percibida posteriormente por el pueblo como mártir y santa al ser capaz de comulgar con él: «vosotros y yo somos lo mismo»?

Finalmente, en el tercer acto, tras los parlamentos alucinados dirigidos a los dos retratos que presiden el escenario, recordemos, los de Isabel la Católica y Carlos V, la reina muere cristianamente un Viernes Santo al confesar su criterio religioso con la asistencia del padre jesuita san Francisco de Borja.

${ }^{3}$ Así consta en la acotación de la obra para el primer acto. Cito de aquí en adelante por la edición manejada, B. Pérez Galdós (2010), p. 39. Dicha edición, por otra parte, es a todas luces mejorable debido a la numerosa cantidad de erratas y descuidos en el texto.

${ }^{4}$ Entre la ingente bibliografía que se ocupa de Juana de Castilla desde la vertiente historicista, destacan los estudios de M. Fernández Álvarez (2000) y B. Aram (2001).

${ }^{5}$ B. Pérez Galdós (2010), p. 40.

${ }^{6}$ B. Pérez Galdós (2010), p. 41.

${ }^{7}$ J. Gutiérrez (1974), p. 210.

${ }^{8}$ B. Pérez Galdós (2010), p. 62.

${ }^{9}$ B. Pérez Galdós (2010), p. 58. 
Pero más allá de la cita en el prólogo de Salaverría ¿de dónde procede el interés galdosiano por subir a las tablas su particular lectura del mito? En una entrevista concedida unos meses después del estreno de la obra al periódico canario La Pren$s a$, Galdós afirma que fue un viaje a «un poblachón muy viejo, que se llama Madrigal de las Altas Torres» — pueblo, por cierto, donde nació Isabel la Católica- el que le ratificó su idea de escribir el drama. Su posterior visita a Tordesillas y Simancas hizo que el escritor comenzara a sentirse atraído «por el espíritu de aquella mujer extraordinaria», para lo cual «como ya yo no podía leer, hice que me leyeran muchos libros en que se hablaba de su vida en el palacio de Tordesillas» ${ }^{10}$.

Efectivamente, esta obsesión por la reina no era novedad para un Galdós ya próximo a la vejez, puesto que, al examinar su biblioteca, el crítico Rodolfo Cardona encontró «lo profusamente marcado que estaba de la mano de don Benito» ${ }^{11}$ el libro de Antonio Rodríguez Villa titulado La Reina Doña Juana la Loca, un estudio histórico aparecido en 1892, donde se inserta la conocida frase «fue loca sí, pero loca de amor», que se unía a los escritos por G. A. Bergenroth y Louis Prosper Gachard sobre la figura de la reina ${ }^{12}$. Emilia Pardo Bazán elaboró un artículo-reseña sobre este estudio en su Nuevo Teatro Crítico ${ }^{13}$ donde se puede leer lo siguiente:

En una palabra: Juana la Loca sería la más conmovedora y sublime de las heroínas de Shakespeare si este semidiós literario no hubiese reservado su musa para narrar los infortunios (menos trágicos) de otra hija de los Reyes Católicos: Catalina de Aragón la repudiada [...]. Pradilla en un lienzo, Tamayo en un drama, intentaron expresar la aterradora poesía de la lúgubre odisea de una demente de amor, en compañía de un muerto [...], grandes artistas son de seguro Tamayo y Pradilla, pero el asunto sobrepasa su inspiración. Lo repito: sólo Shakespeare podría dar forma en las regiones del arte a Doña Juana la Loca ${ }^{14}$.

Ciertamente, los tópicos románticos sobre una Juana enajenada de amor —Pardo Bazán llegó a definirla como una «Quijote del amor conyugal»— se habían llevado

\footnotetext{
${ }^{10}$ Todas las citas proceden de la entrevista realizada a Galdós en el diario canario La Prensa por el periodista J. M. Benítez Toledo, titulada «Hablando con Galdós», aparecida el sábado 15 de junio de 1918.

${ }^{11}$ R. Cardona (1977), p. 463.

${ }^{12}$ Estos estudios, que indagaban en el mito desde la óptica histórica y literaria influenciados por el Romanticismo, son los de G. A. Bergenroth (1862), L. P. Gachard (1869, diversos artículos) y, finalmente, A. Rodríguez Villa (1892).

${ }^{13}$ E. Pardo Bazán (1892), pp. 67-105.

${ }^{14}$ E. Pardo Bazán (1892), p. 68. El drama de Shakespeare al que se refiere Pardo Bazán es Henry VIII or all is true, escrito en colaboración con John Fletcher donde se trata el divorcio de Catalina de Aragón, la pequeña de las cuatro hijas de los Reyes Católicos.
} 
tanto al teatro por Manuel Tamayo y Baus con su Locura de amor $(1855)^{15}$, como también al lienzo por Lorenzo Vallés con su Demencia de doña Juana de Castilla (1866) o el conocido Doña Juana la Loca de Francisco Pradilla $(1877)^{16}$. Más aún, el mito fue llevado tempranamente a las modernas pantallas de cine, donde Ricardo Baños filmaría en 1909 su película Locura de amor ${ }^{17}$.

Sin embargo, la propuesta literaria de Galdós hábilmente escamotea cualquier interpretación sobre la popular «locura de amor» de Juana, pues ni siquiera se hace ni una sola alusión a Felipe el Hermoso en toda la obra. Es más, para el canario, lejos de aquellos que consideran anacrónicamente que la reina sufrió de esquizofrenia ${ }^{18}$, Juana no está loca, sino que solo vive en la indefinición del tiempo a causa de los muchos años: «mi cabeza es un libro, en el cual no falta ninguna página, sólo que la numeración está borrada y las fechas son para mí letra muerta» ${ }^{19}$. Además, Galdós juega con la idea de demencia expuesta por Erasmo en su Elogio de la locu$r a$, donde se establecen dos tipos de locura, una de la que brotan las malas acciones, los crímenes y las guerras y otra muy distinta que permite aliviar en sus infortunios a aquellos que más sufren, como es el caso de la reina, cautiva la mitad de su vida, con el fin de perder la conciencia de sus males:

Pero hay otra locura muy distinta que procede de mí, y que por todos es apetecida con la mayor ansiedad. Manifiéstase ordinariamente por cierto alegre extravío de la razón, que a un mismo tiempo libra al alma de angustiosos cuidados y la sumerge en un mar de delicias. Tal extravío es el que, como un gran favor de los dioses, pedía Cicerón en sus Cartas a Ático, a fin de perder la conciencia de sus muchas adversidades ${ }^{20}$.

${ }^{15}$ En 1855, Manuel Tamayo y Baus estrena Locura de amor con notable éxito. También en 1864 Ramón Franquelo sube a las tablas Doña Juana la Loca: drama histórico dividido en seis cuadros y escrito en verso, por lo cual el tópico de Juana la Loca como personaje romántico enajenado de amor es más que palpable.

${ }^{16}$ Ambos lienzos pueden ser contemplados en el Museo del Prado gracias a la ampliación de sus salas.

${ }^{17}$ Posteriormente aparecería la homónima película Locura de amor (1948), de Juan de Orduña, con Aurora Bautista y Fernando Rey como Juana la Loca y Felipe el Hermoso. Para ver las concomitancias de la obra de Tamayo, Galdós y Orduña, J. Labanyi (2001).

${ }^{18}$ Sobre este tema se han escritos numerosos artículos (y también desvaríos debido a las consideraciones anacrónicas que en algunos casos se pretenden). La corriente crítica actual sobre el tema, encabezada por M. Á. Zalama (2010), apunta a la esquizofrenia sufrida por la reina frente a otro sector crítico que vio en la locura de amor un arma de instrumentalización política esgrimida por aquellos que la volvieron loca, tendencia sugerida por M. Fernández Álvarez (2000), pp. 141 y ss., o B. Aram (2001), p. 119 y ss.

${ }^{19}$ B. Pérez Galdós (2010), p. 46.

${ }^{20}$ E. de Rotterdam (1985), p. 156. 
A esta idea, Galdós añade otra, que podríamos denominar como «locura sublime», por la cual «Erasmo celebra la locura llamando locos a los grandes héroes que han enaltecido la humanidad» $»^{21}$. Frente a tal aseveración, Juana afirma que «por eso yo no me tengo por loca, pues en mi larga vida nada he podido hacer que se destacara de lo común y vulgar», al contrario que su madre, Isabel la Católica ${ }^{22}$. De esta forma, Juana se relaciona con esos «cuerdos-locos» de los que tanto gustó Galdós, esos que en su supuesta locura son los únicos que llevan la razón, aquellos que viven alejados de la norma ${ }^{23}$.

Por otra parte, la lectura erasmista y la total desatención de los oficios religiosos llevan a considerar otro tema fundamental en la obra, es decir, la «supuesta» herejía de Juana de Castilla, ya que por «empapar mi conciencia en esa obra, han dado aquí en la flor de señalarme públicamente como hereje» ${ }^{24}$. Sin embargo, esa herejía tan solo es heterodoxia, puesto que la idea religiosa de la reina, como la de Galdós, no se amolda a la impuesta y opta por vivir su fe de una manera personal, más espiritual y tolerante como reza en su particular credo:

Quiero el agua pura y limpia, como la que cae del cielo cuando lloran las nubes para fertilizar la tierra y purificar todas las cosas; quiero el agua traída por la divina esencia, licor no contaminado aún por las turbulencias de los ríos, que arrastran en su corriente todas las malicias, todas las miserias humanas. En esta idea se funda mi criterio religioso ${ }^{25}$.

Dicha opinión se complementa con el parlamento de san Francisco de Borja, quien asegura a la reina que:

En el libro de Erasmo nada se lee contrario al dogma. Lo que hay es una sátira mordaz contra los teólogos enrevesados, los canonistas insustanciales, las beatas histéricas y los predicadores truculentos, que han desvirtuado la divina sencillez con artilugios retóricos ${ }^{26}$.

${ }^{21}$ B. Pérez Galdós (2010), p. 74.

${ }^{22}$ B. Pérez Galdós (2010), p. 74.

${ }^{23}$ B. Pérez Galdós (2010), p. 74. A Galdós siempre le interesó el tratamiento de estos «cuerdos locos», definidos como «los que se niegan a ajustarse a las normas vigentes, sea por rebelión, sea por superioridad, sea por falta de juicio», J. Labanyi (2001), p. 16.

${ }^{24}$ B. Pérez Galdós (2010), p. 74.

${ }^{25}$ B. Pérez Galdós (2010), p. 73.

${ }^{26}$ B. Pérez Galdós (2010), p. 74. Las cursivas son mías, ya que en estas palabras podemos oír el eco de las pronunciadas por otros personajes galdosianos censurados en su férreo concepto religioso como, verbigracia, doña Perfecta y don Inocencio en la obra homónima o la familia Lantigua de Gloria. 
En el trasfondo de estas palabras está un Galdós que propone un nuevo ejemplo de religiosidad interior, basado en las nobles acciones y el encuentro con los semejantes, pues: ¿¿No es esto virtud? ¿No es humildad? ¿No es cristianismo? ¿No es esto desprecio de las vanidades terrenas para elevar el espíritu a lo divino, a lo eterno? $\rangle^{27}$.

Así las cosas, la gradación simbólica del personaje aumenta al presentar ciertas concomitancias cristológicas, hasta llegar a la proclamación de su santidad. Este matiz se aprecia especialmente en el segundo acto, donde una reina cuerda, comprensiva y de «cristiana mansedumbre», exclama como Cristo: «Dejad, dejad que los niños se acerquen a mí» ${ }^{28}$; de igual modo no duda en ser piadosa y repartir lo que tiene entre quienes más lo necesitan: «recoge todo lo que me resta de mi escaso caudal y repárteselo entre esta gente infeliz» ${ }^{29}$. En resumen, en estas similitudes se aprecia la obsesión de Galdós por una doctrina moderna, tolerante y reformadora, no contaminada por los preceptos más rígidos de la Iglesia ${ }^{30}$, donde «la observancia de las virtudes cristianas, la constante práctica de la caridad, el amor a los humildes, la paciencia y resignación en las desgracias» de la reina llevan al pueblo a exclamar: «iEs una santa!» ${ }^{31}$. Es más, para Galdós, Juana está más cerca del cristianismo que todos aquellos que basan su religión en lo externo, por lo que su fuerza evangélica ha merecido el título de santidad pues, según sus palabras, «yo llamo santa a doña Juana la Loca, porque, para mí, su grandeza espiritual es de las que no deja lugar a dudas» ${ }^{32}$.

\section{3. «La historia de reyes y personajes es inesperada»: Juana la Loca y la super- historia}

Por su parte, Ramón Gómez de la Serna publicó primeramente en Buenos Aires en 1944 y más tarde, en 1949, en Madrid, siete novelitas reunidas bajo el título Doña Juana la Loca (seis novelas superhistóricas). «¿Por qué ha prescindido la historia de la voz de las reinas, cuando en ese detalle hay algo definitivo?», se pregunta-

\footnotetext{
${ }^{27}$ B. Pérez Galdós (2010), p. 42.

${ }^{28}$ B. Pérez Galdós (2010), p. 61.

${ }^{29}$ B. Pérez Galdós (2010), p. 66.
}

${ }^{30}$ Efectivamente, también Juana guarda similitudes con otro personaje galdosiano, es decir, la protagonista de Gloria, ya que, igualmente, se encuadra en Semana Santa el conflicto entre Gloria y Daniel Morton. El Viernes Santo, Gloria ha decidido morir para el mundo con su entrada al convento aunque, finalmente, morirá el Domingo de Resurrección, cuando el cura entone el Gloria in excelsis Deo, en pleno momento de esperanza, cuando el amor fraternal universal parece posible en su realización. Sin embargo, en negra paradoja, será el antagonismo religioso lo que cause su muerte. Para más detalles sobre la concomitancia de esta obra teatral con Gloria véase R. Domínguez Quintana (2005), pp. 476-485.

${ }^{31}$ B. Pérez Galdós (2010), p. 67.

${ }^{32}$ Así consta en la citada entrevista al diario La Prensa, ver J. M. Benítez Toledo (1918). 
ba don Ramón a propósito de otra Juana, reina igualmente polémica, conocida como La Beltraneja ${ }^{33}$. La mayoría de estos relatos van a estar protagonizados por mujeres a las que, aparte de ofrecerles voz, Gómez de la Serna inventa una personalidad y un destino posibles pero distintos a los fijados por la historia en un ejercicio de desmitificación y alejamiento de la historiografía oficial para acercarse a la historia verdadera, denominada en concepción ramoniana la «verdad vital» ${ }^{34}$ : «hay que evitar esa cosa machacona de la novelística y obrar por momentos interesantes, diciendo verdades urgentes y sobrepasadoras de la historia» ${ }^{35}$.

En el caso de Juana la original mirada incide en no considerarla enajenada — «no era una loca, sino una enamorada ${ }^{36}$-, y en añadir una nueva perspectiva del mito en su temor y obsesión por la muerte. Más aún, la reescritura del personaje lleva a don Ramón a permitirse la licencia de imaginar un nuevo final para la reina bajo el membrete de lo superhistórico, donde la deliberada omisión de los hechos se realiza no por desconocimiento, sino por subversión con los cánones históricos ya conocidos.

Del mismo modo que Galdós gestó por largo tiempo su obra y se interesó por el mito de Juana la Loca, Gómez de la Serna parece estar fascinado por el personaje desde la cuna, ya que en casa de la abuela de don Ramón - hermana de la poeta Carolina Coronado - había una reproducción del archiconocido cuadro de Pradilla. Así, en 1942 ofrece una conferencia sobre Juana en la Asociación Amigos del Arte, «quizá la mejor conferencia de mi vida» ${ }^{37}$, a la hay que sumar esta novelita superhistórica además de un capítulo de la autobiografía del autor, Automoribundia ${ }^{38}$, inclusión que el propio autor justifica debido a «esas tías mías que eran Doña Juana la Loca y por causa del cuadro colocado en el portal de mi torreón de Velázquez $4 »^{39}$. Ese mismo cuadro de Pradilla, que «estaba en todos los hogares», le sirve como pretexto en dicho capítulo para reflexionar acerca del personaje y la presencia del lienzo en los hogares de las viudas:

¿Por qué habiendo tantos hechos históricos representados por la pintura los dueños de casa españoles elegían ese oscuro cuadro en que la reina parece estar asando a la parrilla en medio del mar de Castilla y en pleno ocaso el cadáver de su augusto esposo? [...]. Me iba convenciendo, a medida de que pasaban los años, que

\footnotetext{
${ }^{33}$ R. Gómez de la Serna (2002), p. 397.

${ }^{34}$ En torno al concepto de historia y vida como papeles antagónicos, véase E. Serrano Asenjo (2008), p. 153 y ss.

${ }^{35}$ R. Gómez de la Serna (1975), p. 356.

${ }^{36}$ R. Gómez de la Serna (2002), p. 312.

${ }^{37}$ R. Gómez de la Serna (1998), p. 705.

${ }^{38}$ Se trata del capítulo LII de la «autobiografía» de don Ramón, titulada Automoribundia, R. Gómez de la Serna (1998), pp. 439-442.

${ }^{39}$ R. Gómez de la Serna (1998), p. 442.
} 
lo que había que encontrar era una Doña Juana la Loca virginal, modesta y enlutada — no demasiado loca ni huérfana - que nos prometiese para el morir tan abnegada existencia [...]. Doña Juana la Loca ante mí, frente a su paisaje de ocaso, me planteaba la cuestión de si una reina puede estar loca ${ }^{40}$.

En 1944 y dentro de la etapa de «novelismo» del autor ${ }^{41}$, Gómez de la Serna, admirador de las teorías de Sigmund Freud y sus discípulos surrealistas, se acerca a la novela histórica a partir de un mito que exige del lector una valoración inicial y una reflexión crítica final —en este caso, la supuesta locura de amor del personaje- para apartarse de la historia como magistra vitae y acudir a la «verdad vital», desde la libertad y originalidad que le permite al autor la etiqueta de lo superhistórico. La novelita, desarrollada en cinco capítulos, comienza al presentarnos en los dos primeros a una reina cuya «única obsesión era la muerte» desde muy niña, cuando la por entonces infanta quería probarse el traje de su esqueleto, preguntaba a sus maestros no por los latines sino por la Parca y colocaba tapices para que la muerte no se colara por ninguna rendija. A esta, hay que sumar otra obsesión: su amor desmedido y los celos por su infiel marido ya que «el hermoso tenía su sed de cerveza y de mujeres rubias», para lo cual, según don Ramón, la propia Juana se hizo traer un tinte de Venecia con el que convertirse en rubia «en medio del asombro del rey, que así la encontró más blanca que todas las rubias» ${ }^{42}$.

La muerte de Felipe hace que la reina comience «la sierpe interminable de su destino», ya que emprende su deambular por tierras de Castilla, ese huir de la muerte con la muerte a cuestas, con el cadáver de su marido, en esa «angustia de seguir viviendo viuda» al tiempo que intenta huir de la locura:

Doña Juana apresuraba el paso porque por los puentes se pasa de la razón a la locura, y temía tirarse por ellos a la Historia, que es adonde se tiran los suicidas, y no a esa insignificante agua que pasa por ellos y les cree castillos. Solo echaba una mirada de desconfianza a sus aguas, porque ella sabía bien que los ríos se llevan el tiempo, los muertos y las espadas ${ }^{43}$.

Juana acabará asumiendo esa supuesta locura como dolor por la ausencia de su marido ya que «no se aviene a transigir con la muerte, a concederle su presa real» ${ }^{44}$.

\footnotetext{
${ }^{40}$ R. Gómez de la Serna (1998), p. 439.

${ }^{41}$ Esta etapa creativa en la obra de Gómez de la Serna se desarrolla entre 1927 y 1947 mediante novelas cortas y series novelísticas, entre las que se incluyen las falsas novelas, las novelas de la nebulosa y las novelas superhistóricas, que presentan una gran originalidad y libertad a la hora de enfrentarse con la verdad histórica hasta el punto de enmendarla en lo que considere oportuno.

${ }^{42}$ R. Gómez de la Serna (2002), pp. 301 y 302.

${ }^{43}$ R. Gómez de la Serna (2002), p. 311.

${ }^{44}$ R. Gómez de la Serna (1998), p. 441.
} 
Esa enajenación no es otra cosa que su imposibilidad a la hora de llorar puesto que «de ese horrorizarse sin sollozos sale la locura» ${ }^{45}$, según la explicación del novelista. A continuación, se suceden los episodios más tópicos del mito, como el de la abadesa del Monasterio de las Huelgas quien, fascinada por querer ver el rostro de Felipe el Hermoso, es sorprendida por la reina o también recordemos la anécdota ante la negativa de la reina de ir al reino de León porque, como Felipe murió al tomar un vaso de agua, esta muerte humillante para un rey se esconde para inventar otra: el ataque de un león que hirió de muerte al monarca, lo cual hacía exclamar a la reina «¡León, no! ¡León, no!» al querer entrar en el reino castellano ${ }^{46}$.

Finalmente, ante la llegada de los innominados nuevos reyes, Juana es encerrada en numerosos castillos hasta acabar en Torresoles, trasunto de Tordesillas, solo por su amor más allá de la muerte y no por su locura. Así, el personaje se dignifica a través de un nuevo final donde la reina, en un acto de lucidez, se arroja desde lo alto de la torre de la catedral para acabar muriendo «sobre el féretro de su querido y hermoso esposo» ${ }^{47}$.

De este modo, la versión heterodoxa del mito en esta narración de Gómez de la Serna es posible a través de la superhistoria, que no es otra cosa que una fabulación «superidealista y superconsciente» de la historia, concebida como un río que se dirige hacia el futuro, lo que está por venir. Más allá del concepto, la técnica le permite a don Ramón ofrecernos una nueva visión del personaje y del comportamiento de la reina así como crear un final alternativo al hacer añicos los presupuestos de la novela histórica convencional y acortar el sufrimiento de los casi cincuenta años de reclusión de esta reina en Tordesillas con su precipitado suicidio. Asimismo, al mezclar los sucesos históricos con los hipotéticos, el superhistoriador se rebela contra la historiografía tradicional: «La superhistoria es escaparse de la Historia confinada y que resulta tan pobre por rodearla de límites y de elementos intransformables e intransferibles cuando puede acogerse a la constante de la improvisación» ${ }^{48}$.

\section{Dos maneras de interpretar un mito. Conclusión}

Si la supuesta herejía y locura de la reina Juana son los ejes temáticos en la obra de Galdós, en Gómez de la Serna la historia pivotará en torno a la obsesión por la muerte y al amor, cuyo dolor en la pérdida será la causante de su locura. Pero más allá de estas originales temáticas, alejadas de los tópicos románticos, en el fondo de ambas obras late una novedosa reflexión histórica que surge a raíz del personaje. Juana de Castilla es el símbolo que Galdós utiliza para mostrar el conflicto de la

${ }^{45}$ R. Gómez de la Serna (2002), p. 304.

${ }^{46}$ R. Gómez de la Serna (2002), p. 310.

${ }^{47}$ R. Gómez de la Serna (2002), p. 313.

${ }^{48}$ R. Gómez de la Serna (2002), p. 295. 
historia de España y su revisión, hilo del que tirar para reflexionar sobre el momento presente. De esta manera, la identificación de Juana con Castilla es total, y como tal es presentada: «Castilla debe ser inseparable de esta ilustre señora, hija y heredera de la gran Isabel ${ }^{49}$. Desde la perspectiva imaginada de la alternativa que Castilla no siguió, en ese paréntesis entre la augusta Isabel la Católica y el emperador Carlos $\mathrm{V}$, Juana es el eslabón soñado, todo aquello que pudo haber sido y no fue. Es más, la obra termina con la pasión y muerte de Juana un Viernes Santo, «el día más triste de la cristiandad», en paralelo asimismo con la muerte de una España posible.

La obra galdosiana, definida por el propio autor como «poema dramático» ${ }^{50}, \mathrm{y}$ por otros calificada de «parábola»o «ensoñación histórica» ${ }^{51}$, despliega una bella utopía y un cierto revisionismo histórico que permite enlazar a Galdós y a su verdad estética con el concepto unamuniano de «intrahistoria» ${ }^{52}$, esto es, la decantación de lo histórico, el poso en el cedazo de lo cotidiano o la posterior "vividura» de Américo Castro, es decir, el modo cómo, al intentar regenerar y recrear la alternativa histórica que Castilla no siguió ${ }^{53}$. El ejemplo lo tenemos en el segundo acto de la obra, en la charla relajada y cotidiana de una reina que se acerca a su pueblo para conocer sus preocupaciones y quehaceres diarios.

Si bien Azorín o Pérez de Ayala ya habían reflexionado sobre este particular, la obligación social y moral ${ }^{54}$ de Galdós le lleva a enjuiciar tanto a Isabel la Católica como a Carlos $\mathrm{V}$ en los dos monólogos alucinados que tiene Juana en el tercer acto, justo antes de morir. Así traza el devenir de la historia de España desde su madre a su hijo, a quien dedica unas duras palabras llenas de dolor ante el olvido en que ha estado sumida tanto tiempo. La extremada ortodoxia ejercida por Isabel la Católica, aumentada en su celo por su nieto, para Galdós fue más que un error, que se deja notar incluso en la sociedad contemporánea ${ }^{55}$ :

${ }^{49}$ B. Pérez Galdós (2010), p. 63.

${ }^{50}$ Este calificativo se encuentra en la crítica teatral de J. Alsina (1918), p. 9.

51 J. Rubio Jiménez (2013), p. 3.

52 J. Artiles (1977).

${ }^{53}$ El concepto de «intrahistoria» lo acuña Unamuno en su obra En torno al casticismo (1895) y también los noventayochistas reflexionaron sobre este concepto: Azorín, Pérez de Ayala e incluso Alfonso X el Sabio ya matizaba la definición de historia añadiendo «a la gente común». Posteriormente, A. Castro (1980), en su obra La realidad histórica de Espa$\tilde{n} a$, introduce el término vividura, «el modo cómo» se vive la historia.

${ }^{54}$ S. Finkenthal (1974), p. 133.

${ }^{55}$ Parece de sumo interés esta interpretación galdosiana, que acerca su postura a la posterior de Américo Castro, quien postuló que a partir de los Reyes Católicos (y más concretamente de la muerte del heredero, el príncipe don Juan) empezaba la «edad conflictiva», la alternativa histórica que finalmente no pudo ser. 
Su principal error fue aquel empeño en salvar las almas, no sólo de los españoles de su tiempo, sino de todos los que hemos venido después. Este afán de regir las conciencias presentes y futuras es una extralimitación, un abuso de facultades políticas, que hoy no puede ser perdonado. [...] Aquella excelente señora, reina famosa entre todas las reinas, espejo de las mujeres, hizo ciertamente grandes cosas; pero le faltó una, la principal y más importante para el porvenir de sus súbditos. No vio, o no la dejaron ver, que si antes de morir hubiera desatado nuestras conciencias, habría hecho más por nosotros que descubriendo cien Américas y conquistando doscientas Granadas ${ }^{56}$.

En resumen, Galdós retoma en esta obra final un verdadero ananké presente en toda su ideología, esto es, el concepto de historia y su reflexión profunda, es su verdad estética, el «verdadero sentir y pensar de los pueblos» frente a las crónicas o la historia oficial. Así lo expresa:

[La Historia] está en el vivir lento y casi siempre doloroso de la sociedad, en lo que hacen todos y en lo que hace cada uno. [...] Los libros, que forman la capa papirácea de este siglo, como ha dicho un sabio, nos vuelven locos con su mucho hablar de los grandes hombres, de si hicieron esto o lo otro, o dijeron tal o cual cosa. Sabemos por ellos las acciones culminantes, que siempre son batallas, carnicerías horrendas y empalagosos cuentos de reyes y de dinastias, que agitan al mundo con sus riñas y con sus casamientos y, entre tanto, la vida interna permanece oscura, olvidada, sepultada ${ }^{57}$.

Por su parte, Gómez de la Serna se sirve de lo superhistórico, al que añade su particular «verdad vital». Así, la superhistoria permite subvertir los hechos conocidos al incidir en los tópicos también desde el humorismo. De este modo, el autor subraya el confinamiento de la reina, porque «para eso estaba llena de castillos Castilla, para encerrar a la reina intemperante, que no quería dejar de reinar viajando por sus caminos con su lema de amor» ${ }^{58}$. También la tergiversación política del testamento de la reina católica — según diferentes intereses en el juego de tronos castellano - tiene su hueco en la novelita: "Castillos llenos de testamentos que crecen y que amenazan con no dejar entrar un día por cómo se desarrollan en codicilos, pleitos y apelaciones»; asimismo está presente la revuelta comunera, aquella por la que Juana perdió la oportunidad de reinar al ser aclamada como legítima heredera: «los pueblos encrespaban sus voces alrededor de los castillos de su confi-

\footnotetext{
${ }^{56}$ B. Pérez Galdós, prólogo a José María Salaverría (1907), p. XXIII.

${ }^{57}$ Apud J. Artiles (1977), p. 213. Las cursivas son mías.

${ }^{58}$ R. Gómez de la Serna (2002), p. 312. De hecho, se ha convertido en tópico presente en varios ensayos y estudios la negativa de la reina a «acercarse a ciudades amuralladas, por temor a quedar presa en una de ellas», así en V. Márquez de la Plata (2014), p. 139 (y también p. 143).
} 
namiento y entonces había que desterrarla a otros en sitios desérticos» ${ }^{59}$. Pero sin duda, será la obsesión por escapar de la muerte lo que más destaque del personaje:

Ideas encresponadas venían a mi mente y pensando pensando encontré esa calidad de llovido por la muerte que tiene ese velo y cómo sirve para evitar que pique a la viuda la mosca de la muerte que picó a su marido ${ }^{60}$.

De esta manera, la reina acaba encerrada en la iglesia donde estaba depositado el féretro de Felipe el Hermoso, esto es, el Monasterio de Santa Clara de Tordesillas, en la «alta linterna de la nave» donde podía contemplar «su querido baúl de amor» ${ }^{61}$. Allí «se veía que aguardaban para hacerle el mausoleo a él a que muriese ella, como si se quisiese hacer una economía escultórica con los consortes coronados», donde la pincelada humorística es más que evidente. Sin embargo, la subversión de la historia le lleva al novelista a hacer que «la reina calumniada de loca» se suicide junto a su esposo para concluir que «así quedó bien rematada su supuesta locura, que no sabrá epilogar la Historia jamás» ${ }^{62}$.

Silencio, oscuridad, olvido. Eso es para Galdós la historia no oficial, particular, lo que trataron de desempolvar los noventayochistas, lo mismo que retoma Gómez de la Serna con su superhistoria ya que «en mis delirios de superhistoriador he visto muy claro ese fondo de agua de la Historia; su drama, sus ráfagas, sus mentiras que son verdades y sus verdades estultas ${ }^{63}$. En definitiva, esa agua profunda, enturbiada por el ir y venir de la historia y sus sesgos, puede ser reinterpretada gracias a la luz deslumbrante de la literatura para mostrarnos lo que pudo haber sido y no fue, o lo que quizá fue y la historia silencia.

\section{OBRAS CITADAS}

AlsinA, José: «Santa Juana de Castilla», La Vanguardia, martes 28 de mayo de 1918, pp. 8-9.

${ }^{59}$ R. Gómez de la Serna (2002), p. 312.

${ }^{60}$ R. Gómez de la Serna (1998), p. 441.

${ }^{61}$ Se vuelve a incidir en esta idea en R. Gómez de la Serna (1998), p. 441: «Solo pide que se pueda ver el féretro del esposo desde la ventana de su alcoba - lo mismo que consiguió mi tía Carolina en Portugal, en el palacio de la Mitra en el que su alcoba daba a la capilla donde estaba depositado sobre un diván el silencioso-, y allí va a pasar cuarenta y siete años de viuda inconsolable, pensando en su Felipe el Hermoso, sin sentirse destronada y en prisión de convento y palacio»».

${ }^{62}$ R. Gómez de la Serna (2002), p. 313.

${ }^{63}$ R. Gómez de la Serna (2002) p. 293. 
ARAM, Bethany: La reina Juana: gobierno, piedad y dinastía, Madrid, Marcial Pons, 2001. : «Queen Juana: Legend and History», en María A. Gómez, Santiago JuanNavarro y Phyllis Zatlin (eds.), Juana of Castile. History and Myth of the Mad Queen, Lewisburg, Bucknell UP, 2008, pp. 33-45.

ARTILES, Jenaro: «La intrahistoria: de Galdós a Unamuno», en Actas del primer congreso internacional de estudios galdosianos, Las Palmas, Ediciones del Cabildo, 1977, pp. 201-220.

Bergenroth, G. A.: Letters, Despatches, and State Papers Relating to the Negotiations Between England and Spain Preserved in the Archives at Simancas and Elsewhere, London, Longmans, Reader and Dyer, 1862.

Benítez Toledo, J. M.: «Hablando con Galdós», La Prensa, 15 de junio de 1918, p. 1.

CARDONA, Rodolfo: «Fuentes históricas de Santa Juana de Castilla», en Actas del primer congreso internacional de estudios galdosianos, Las Palmas, Ediciones del Cabildo, 1977, pp. 462-467.

CASTRO, Américo: La realidad histórica de España, México, Porrúa, 1980.

Domínguez QuinTANA, Rubén: «De Gloria a Santa Juana de Castilla: dos modelos religiosos en la mujer galdosiana», en VIII Congreso Internacional Galdosiano, 2005, pp. 476-485.

FERNÁNDEZ ÁlVAREZ, Manuel: Juana la Loca. La cautiva de Tordesillas, Madrid, Espasa, 2000.

FinKenthal, Stanley: «Santa Juana de Castilla: Galdós' lastplay», en Anales Galdosianos, IX (1974), pp. 125-134.

GACHARD, Louis Prosper: «Sur la question de Jeanne la Folle», Académie Royale de Belgique, Extr. des Bulletins, 5 (1869).

: «Sur Jeanne la Folle et la publication de M. Bergenroth», Académie Royale de Belgique, Extr. des Bulletins, 9 y 10 (1869).

GÓMEZ DE LA SERNA, Ramón: Ismos, Madrid, Guadarrama, 1975.

: Automoribundia, Ioana Zlotescu (ed.), Barcelona, Círculo de Lectores, Galaxia Gutenberg, 1998.

: Juana la Loca y otras seis novelas superhistóricas, en Obras Completas, Ioana Zlotescu (ed.), Barcelona, Círculo de Lectores, Galaxia Gutenberg, 2002, pp. 290-313.

GuTIÉRREZ, Jesús: «La "Pasión" de Juana de Castilla», en Estudios Escénicos, 18 (1974), pp. 203-214.

LABANYI, Jo: «La modernización de Juana la Loca: la última obra de Galdós, Santa Juana de Castilla (1918), entre la Locura de amor de Tamayo y Baus (1855) y Locura de amor de Orduña (1948)», en VII Congreso Internacional Galdosiano, 2001, pp. 16-30.

MÁRQueZ DE la Plata, Vicenta: El trágico destino de los hijos de los Reyes Católicos, Madrid, Santillana, 2014. 
PARDO BAZÁN, Emilia: «Un drama psicológico en la historia: Juana la Loca, según los últimos documentos», en Nuevo Teatro Crítico, II, 14 (1892), pp. 67-105.

PÉrez Galdós, Benito: Santa Juana de Castilla, Félix Rebollo Sánchez (ed.), Madrid, Fragua, 2010.

RodRíGUEZ VILlA, Antonio: La reina doña Juana la Loca: estudio histórico, Madrid, Librería de M. Murillo, 1892.

RotTERDAM, Erasmo de: Elogio de la locura, Barcelona, Orbis, 1985.

RUBio JimÉnEZ, Jesús: «Ramón Pérez de Ayala, crítico teatral», en Don Galán, Revista de Investigación teatral, 3 (2013), pp. 1-9. <http://teatro.es/ contenidos/donGalan/donGalanNum3/>

SAlaVerríA, José María: Vieja España (con prólogo de B. Pérez Galdós), Madrid, Sucesores de Hernando, 1907.

SERRANO ASENJO, Enrique: «Unidad y diversidad en Doña Juana la Loca: pasiones vestidas de superhistoria, novela y (auto)biografía», en Ramón Gómez de la Serna y la novela: nuevas perspectivas, Eloy Navarro Domínguez (ed.), Huelva, Universidad, 2008, pp. 145-171.

Unamuno, Miguel de: En torno al casticismo, Biblioteca Nueva, Madrid, 1996.

ZALAMA, Miguel Ángel: Juana I. Arte, poder y cultura en torno a una reina que no gobernó, Centro de Estudios Europa Hispánica, Madrid, 2010. 